\title{
Evidence for age-related deficits in object-location binding during place recognition
}

Veronica Muffato ${ }^{1,2}$, Christopher Hilton ${ }^{2}$, Chiara Meneghetti ${ }^{1}$, Rossana De Beni', Jan M. Wiener ${ }^{2}$

${ }^{1}$ Department of General Psychology, University of Padova, Italy

${ }^{2}$ Psychology Department, Ageing and Dementia Research Centre, Bournemouth University, UK

Correspondence should be addressed to:

Veronica Muffato (ORCID ID: orcid.org/0000-0003-2696-4871), veronica.muffato@unipd.it, Department of General Psychology, University of Padova, Via Venezia, 8, 35131, Padova, Italy

Tel +390498276941

Running head: Place recognition in young and older adults 


\begin{abstract}
Deciding whether a place is the same or different than places encountered previously is a common task in daily navigation which requires to develop knowledge about the locations of objects (object-location binding) and to recognize places from different perspectives. These abilities rely on hippocampal functioning which is susceptible to increasing age. Thus, the question of the present study is how they both together impact on place recognition in aging. Forty people aged 20-29, 44 aged 60-69, and 32 aged 70-79 were presented with places consisting of 4 different objects during the encoding phase. In the test phase, they were then presented with a second place and had to decide whether it was the same or different. Test places were presented from different perspectives $\left(0^{\circ}, 30^{\circ}, 60^{\circ}\right)$ and with different object conditions (same, a swap of two objects, a substitution with a novel object). The sensitivity for detecting changes ( $\left.d^{\prime}\right)$ decreased from 20-29 to 60-69 and to 70-79 years old, and with increasing perspective shifts. Importantly, older adults were less sensitive to object swapping than to object substitution, while young participants did not show any difference. Overall, these results suggest specific age-related difficulties in object-location binding in the context of place recognition.
\end{abstract}

Keywords: place recognition, object-location binding, perspective shift, aging 
The ability to recognize a previously visited place, even if experienced from a viewpoint different to that during initial encoding, is crucial for successful navigation (Waller \& Nadel, 2013). While many places can easily be identified by single distinctive environmental features (i.e. landmarks), other places are recognized by the spatial relationships between a number of more common environmental features. In this study we examined how cognitive aging, which is known to affect navigation and orientation abilities (Lester, Moffat, Wiener, Barnes, \& Wolbers, 2017), impacts on the recognition of places that are defined by a specific spatial arrangement of several objects. In particular, we were interested in how substituting or swapping object locations as well as perspective shifts affected place recognition.

Recognizing a place, defined by a number of objects, requires memory of object identity as well as of their locations (Postma, Kessels, \& van Asselen, 2004). To associate these separate memory systems, the object identity must be bound to their locations (Pertzov, Dong, Peich, \& Husain, 2012). Successful retrieval of object-location representations allows individuals to identify a place on basis of an arrangement of objects and to distinguish it from other, similar arrangements. However, if object-location binding fails, "swap" errors may arise, i.e. errors in which objects are believed to have been in a location occupied by a different object (Pertzov et al., 2012). So far, object-location binding has been studied in small-scale two-dimensional spaces, often with abstract shapes that are presented at different screen positions (Dai, Thomas, \& Taylor, 2018). Here we translated these paradigms into a context more relevant for orientation and navigation. Specifically, we used virtual environments technology to create images of threedimensional places that were defined by the spatial arrangement of different objects and that could be presented from different viewpoints.

The evidence for how aging affects object memory, location memory and object-location binding in small scale space is currently mixed. While some studies report that memory for object 
identity and object locations was unaffected by aging (Mitchell, Johnson, Raye, Mather, \& D'Esposito, 2000), other studies report decreased precision in identifying both object identity (Dai et al., 2018) and location (Pertzov, Heider, Liang, \& Husain, 2015). Similarly, object-location binding has been reported to be preserved in older adults (Ellis, Katz, \& Williams, 1987), whereas other studies suggest that binding performance decreases in older age (Dai et al., 2018; Mitchell et al., 2000). The fact that at least some studies report age-related deficits in object and location memory and object-location binding, raises the important question of whether this process is also involved in declining recognition of three-dimensional spaces or places, therefore potentially contributing to age-related declines in navigation abilities.

Place recognition during everyday navigation is different from remembering and recognizing a layout of objects in 2D space, insofar as places are often experienced from a perspective that differs from that during initial encoding. Such perspective changes can change the visual appearance of a place markedly and typically results in declining place recognition performance (Diwadkar \& McNamara, 1997; Waller, 2006). To recognize a place after a perspective changes, it is not sufficient to compare the current visual image with that during encoding (Friedman \& Waller, 2008). Instead, it has been argued that hippocampal-dependent topographical memories, which represent the spatial relationship between objects locations, allow for place recognition after perspective changes (King, Burgess, Hartley, Vargha-Khadem, \& O’Keefe, 2002; Hartley et al., 2007). As the hippocampus undergoes functional and morphological changes already in typical aging (Klencklen, Després, \& Dufour, 2012), it is not surprising that a series of studies has reported age-related deficits in perspective taking abilities (e.g., Inagaki et al., 2002; Montefinese, Sulpizio, Galati, \& Committeri, 2015; Watanabe, 2011).

Previous studies have investigated age-related changes in spatial perspective taking or object-location binding in isolation. The present study aimed to combine these fields of inquiry to 
investigate how these mechanisms interact and how aging affects object-location binding in the context of 3D place recognition. Specifically, we presented participants with a spatial scene comprised of four different objects during encoding. In the test phase they were then presented with the same or a similar place from the same or a different perspective. Places were changed by either substituting one object with a new object (substitute condition) or by swapping the locations of two objects (swap condition). Participants' task was to indicate whether or not the place had changed.

We expected to replicate earlier findings by showing (i) declining performance with increasing perspective shifts (Diwadkar \& McNamara, 1997); (ii) higher performance in the substitution than the swap condition as the former can be solved solely by object memory, while the latter relies on binding objects to their locations (Pertzov et al., 2012). For the same reason we expected that (iii) perspective shifts affected the swap condition more than the substitute condition, resulting in an interaction between condition and perspective. Overall, we expected (iv) worse performance in the older as compared to the younger participant group (Klencklen et al., 2012). Finally, if aging affected object-location binding also in the context of place recognition, we expected ( $v$ ) an age $\times$ condition interaction, with a stronger performance decrement in the older age group in the swap as compared to the substitute condition.

A total of 116 participants gave their written informed consent in accordance with the Declaration of Helsinki (World Medical Association, 2013) to take part to the study: 40 people aged 20-29 (18 males; $M$ age $=23.35, S D=2.41), 44$ people aged 60-69 $(21$ males; $M$ age $=64.55$, $S D=3.50$ ), and 32 people aged 70-79 (19 males; $M$ age $=72.69, S D=2.48$ ). We have chosen these specific age groups (see Baltes, 1998) based on earlier studies demonstrating an age-related decline in spatial learning from 60 years of age onwards, which accelerates beyond the age of 70 (e.g., Barrash, 1994; Gazova et al., 2013). 
Participants attended two separate sessions, lasting approximately 40 minutes each. In the first session participants completed a socio-demographic questionnaire, the MoCA (older participants only) and the vocabulary test. In the second session, they performed the place recognition task presenting 72 trials in a randomized order (see Figure 1 for places and conditions in the place recognition task).

Insert Figure 1 here

Accuracy in the place recognition task was converted into sensitivity (d') scores (we calculated also response bias, see detailed methods). We ran a linear mixed effects model (LME) analysis for d' scores using the Ime4 package (version 1.1-14; Bates, Machler, Bolker \& Walker, 2015) in R (R Development Core Team, 2013). Fixed effects were age group as a factor $(20-29,60-$ 69, 70-79 years old) coded using successive differences contrast coding, gender as a factor (male, female) coded using sum contrast coding, condition as a factor (swap, substitute) coded using sum contrast coding and perspective shift as a factor $\left(0^{\circ}, 30^{\circ}, 60^{\circ}\right)$ coded using successive differences contrast coding. Participant was included a random factor. We started with an intercept only model and added random by-participant slopes for fixed effects one by one and then added interactions between random slopes. Each random slope or interaction was included only if the model converged and it significantly improved the model (the final model code was: model $=$ Imer (dPrime $\sim$ condition $*$ ageGroup $*$ perspective $*$ gender $+(1+$ perspective + condition (participantNumber), data).

Coefficients, standard errors and t-values for the final model are reported in Table 1 and shows that age group, perspective and condition are all significant predictors of $d^{\prime}$ scores. Specifically, for age group both advances from 20-29 to 60-69 years old, and from 60-69 to 70-79 years old predicts a significant reduction in d' scores. Perspective shift from $0^{\circ}$ to $30^{\circ}$, and from $30^{\circ}$ 
to $60^{\circ}$ significantly predicts a reduction in $d^{\prime}$ prime scores. The significant condition main effect shows that d' scores are significantly lower in the swap condition then in the substitute condition. Importantly, the model reveals a significant age group $\times$ condition interaction. Specifically, this interaction shows that when age changes from 20-29 to 60-69, performance drops more in the swap condition than for the substitute condition (see Figure 1 panel B).

Insert Table 1 and Figure 2 here

Overall, the sensitivity to detect changes in the object layout decreased with increasing perspective shifts and increasing age and was lower when objects swapped locations as compared to situations in which objects were substituted. Our older adults had particular problems with the swap condition, which suggests a specific age-related object-location binding deficit. This effect was present already in our participants aged 60-69 and did not significantly worsen in our older participant group (aged 70-79). Our results demonstrate that older adults show deficits in memory for layouts of objects experienced across different perspectives (in line with Hartley et al., 2007; Montefinese et al., 2015). Age-related neurodegeneration in the hippocampal circuit is crucial for establishing topographical or allocentric spatial memories that provide the viewpoint independence required to recognize places from different perspectives (King et al., 2002).

However, to our knowledge, no study so far has investigated whether object-location binding contributed to the age-related impairments reported in spatial memory for places. Our older age groups were less likely to detect that two objects had been swapped than that one object had been substituted. This cannot be explained by general memory deficits. Instead, it highlights a specific deficit in binding objects to their locations which could also have contributed to age differences reported in earlier studies. Recent reviews highlight the involvement of the left hippocampus and other related brain areas (such as, bilateral medial temporal lobe, Postma \& Van 
Der Ham, 2016; Zimmermann \& Eschen, 2017) in object-location binding, brain areas that are susceptible to age-related functional and anatomical changes (Klencklen et al., 2012).

The performance in the substitute condition was higher than in the swap condition. This was expected as the substitute condition can be solved by object identity memory alone, while the swap condition requires object as well as location memory (Pertzov et al., 2012). It should be noted at this point that there was a trend of declining performance in the older age groups also in the substitute condition. One explanation for this decline is age-related differences in object memory (Dai et al., 2018) which would have also contributed to the overall decline in place recognition performance in older adults. However, as other studies suggested preserved memory for objects/landmarks in older age (e.g., Mitchell et al., 2000), an alternative explanation for this result relates to age-related differences in strategy use when solving the task. The current data does not allow us to distinguish between age-related differences in encoding strategies or agerelated differences in object-location binding, but we are currently running a follow up eyetracking study to address this issue.

We argue that the age $x$ condition interaction resulted from a specific age-related deficit in object-location binding, a cognitive process which is required to solve the swap but not the substitute condition. However, one might argue that our older participants were simply more affected than our young participants by the increased task difficulty in the swap condition, resulting from the additional information processing required, but independent of the specific nature of the addition cognitive processes involved. This explanation, however, seems unlikely, given that the additional difficulty resulting from engaging perspective taking mechanisms is handled equally well by all age groups, i.e. it did not result in an age x perspective interaction. 
Another important point to briefly address here is the role of the hippocampus in pattern completion and pattern separation (Yassa \& Stark, 2011), which is required to discriminate whether a place was identical or different from a place encoded before. Aging is typically associated with a pattern completion bias (Vieweg, Stangl, Howard, \& Wolbers, 2015), which would suggest that older adults produce more miss errors, rather than false positives. In fact response bias analyses (see detailed method) show that our older participants were more conservative (more likely to accept a different place as identical) than our young participants in the swap condition. This result is in line with the idea of an age-related pattern completion bias and our results suggest that declining object-location binding may contribute this bias.

While object-location binding is typically studied with small-scale two-dimensional stimuli (e.g., Dai et al., 2018), we here used virtual environments technology to design three-dimensional places. In other words, we have translated the standard paradigm into a slightly more realistic context that also allowed us to present the places from different viewpoints (Friedman \& Waller, 2008). Recognizing places from viewpoints different to those during encoding is an important ability when navigating. For example, recognizing an intersection from a different perspective when navigating routes that are crossing is crucial for integrating route knowledge into cognitive maps. However, our study did not directly assess participants' ability to navigate, which is a limitation that should be addressed in future studies.

In line with earlier research (Montefinese et al., 2015) we found that performance declined with increasing perspective shifts. Note however, that the size of the effect was more than twice as large between $0^{\circ}$ and $30^{\circ}$ than between $30^{\circ}$ and $60^{\circ}$. These findings are consistent with either the idea of an allocentric representation that provides preferential access from the perspective aligned with the learning viewpoint (Diwadkar \& McNamara, 1997) or with a two abilities account, in which the $0^{\circ}$ condition is solved by a 'simple' image comparison (i.e., the place is stored as a 
visual scene, Milner \& Goodale, 2008), while perspective taking is only being applied if the perspective actually changed. Our current study was not designed to distinguish between these different possible explanations.

Interestingly, we did not find an interaction between age and perspective shifts: while both older age groups performed worse than our younger age group, this difference did not compound with increasing perspective shifts. These findings suggest that the ability to perform perspective taking tasks is preserved in older age (e.g., Watanabe, 2011). These findings are in line with neuropsychological studies which suggest that egocentric perspective use is supported by parietal cortex activation (Postma \& Van Der Ham, 2016), a brain area which is relatively resilient against functional changes resulting from age-related structural changes when compared to the medial temporal lobe (Yamamoto, Fox, Boys, \& Ord, 2019).

Instead - and as discussed above - we argue that performance differences between age groups in our place recognition task relate to other processes involving the ability to form topographic representations, object identity memory and object-location binding.

To conclude, the present study suggests a specific age-related object-location binding - but not a perspective shift - deficit in the context of place recognition.

\section{Detailed Methods}

Participants. Participants met the inclusion criteria requiring them (i) living independently, (ii) healthy as measured through history of diseases capable of causing cognitive, visual, auditory and/or motor impairments (Crook et al., 1986), (iii) cognitively normal function as measured by a score of 26+ on the MoCA (Montreal Cognitive Assessment, Nasreddine et al., 2005) for older 
participants. None of the participants were excluded. Older adults aged 60-69 ( $M$ years of education $=11.18, S D=3.35)$ and $70-79(M=12.19, S D=3.15)$ had a lower education level than the young adults $(M=15.42, S D=2.23), F(2,115)=23.05, \eta^{2}=.29, p<.001$, consistent with the sociodemographic differences due to the cohort effect. All groups, however, showed similar performance $(20-29$ years old: $M=54.55, S D=9.14 ; 60-69$ years old: $M=52.73, S D=9.45 ; 70-79$ years old: $M=54.90, S D=8.78 ; F<1, p=.52$ ) in the vocabulary test (Wechsler, 1981) which assesses crystallized abilities.

Place recognition task. We created eight places using Blender 2.66. Each place depicts the same garden (green grass, light blue sky, and the light of the sun) with four objects in different positions. For each of the places, we created two further places: one with the position of two objects swapped, one with an object substituted with a novel object. Each place was rendered from 5 different viewpoints, the original viewpoint and then from a viewpoint that differed by $30^{\circ}$ and $60^{\circ}$ to the left and to the right (see Figure 1, panel A). The positions of the objects in the place were chosen to minimize occlusion, such that all objects were visible from all viewpoints. The place recognition task was prepared using OpenSesame 3.1.4 (Mathôt, Schreij, \& Theeuwes, 2012). There were 72 trials (see Figure 1, panel B for the time sequence of the trial) comprising of 9 trials for each of the 8 places including 3 trials presented in the same condition (from $0^{\circ}, 30^{\circ}$, and $60^{\circ}$ ), 3 in the swap condition (from $0^{\circ}, 30^{\circ}$, and $60^{\circ}$ ), and 3 in the substitute condition (from $0^{\circ}$, $30^{\circ}$, and $60^{\circ}$; see Figure 1 panel C, for an example of manipulations referring to place 1 ).

Response bias analyses. We calculated response bias and ran a LME analysis using the same factors as in the analyses of $d^{\prime}$ presented in the main text. Coefficients, standard errors and tvalues for the final model are reported in Table 2. It shows a reliable main effect of perspective and condition, while gender and age group were not significant. Specifically, perspective shift from 
$0^{\circ}$ to $30^{\circ}$, and from $30^{\circ}$ to $60^{\circ}$ significantly predicts a reduction bias scores. Response biases are significantly higher in the swap condition then in the substitute condition.

The model also reveals a number of significant interactions. Concerning the age group $x$ condition, older adults groups had a more positive bias than our younger group only in the swap, but not in the substitute condition; see Figure 3 ). Concerning age group $\times$ perspective, people aged 70-79 had a higher positive bias at $0^{\circ}$ than $30^{\circ}$, while people aged $60-69$ had not; the latter had a more higher positive bias at $30^{\circ}$ than $60^{\circ}$, while people aged $20-29$ did not show this. An interaction age $\times$ gender was also found. Specifically, males aged 70-79 had a more positive bias than female aged 70-79, while no difference between males and females was found for people aged 60-69.

Insert Table 2 and Figure 3 here 
Conflict of interest: none.

Data availability: The data that support the findings of this study are available from the corresponding author upon reasonable request. 


\section{References}

Baltes, M. M. (1998). The psychology of the oldest-old: The fourth age. Current Opinion in Psychiatry, 11(4), 411-415. https://doi.org/10.1097/00001504-199807000-00009

Barrash, J. (1994). Age-related decline in route learning ability. Developmental Neuropsychology, 10, 189-201. https://doi.org/10.1080/87565649409540578

Bates, D., Mächler, M., Bolker, B., \& Walker, S. (2015). Fitting Linear Mixed-Effects Models Using Ime4. Journal of Statistical Software, 67(1), 1-48. https://doi.org/10.18637/jss.v067.i01

Crook, T., Bartus, R. T., Ferris, S. H., Whitehouse, P., Cohen, G. D., \& Gershon, S. (1986). Ageassociated memory impairment: Proposed diagnostic criteria and measures of clinical change - report of a national institute of mental health work group. Developmental Neuropsychology, 2, 261-276. https://doi.org/10.1080/87565648609540348

Dai, R., Thomas, A. K., \& Taylor, H. A. (2018). Age-related differences in the use of spatial and categorical relationships in a visuo-spatial working memory task. Memory \& Cognition, 46(5), 809-825. https://doi.org/10.3758/s13421-018-0794-8

Diwadkar, V. A., \& McNamara, T. P. (1997). Viewpoint Dependence in Scene Recognition. Psychological Science, 8(4), 302-307. https://doi.org/10.1111/j.1467-9280.1997.tb00442.x

Dixon, R. A., Bäckman, L., \& Nilsson, L. G. (2004). New Frontiers in Cognitive Aging. Oxford: Oxford University Press.

Ellis, N. R., Katz, E., \& Williams, J. E. (1987). Developmental aspects of memory for spatial location. Journal of Experimental Child Psychology, 44(3), 401-412. doi.org/10.1016/00220965(87)90042-7 
Friedman, A., \& Waller, D. (2008). View combination in scene recognition. Memory and Cognition, 36(3), 467-478. https://doi.org/10.3758/MC.36.3.467

Gazova, I., Laczó, J., Rubinova, E., Mokrisova, I., Hyncicova, E., Andel, R., ... Hort, J. (2013). Spatial navigation in young versus older adults. Frontiers in Aging Neuroscience, 5: 94. https://doi.org/10.3389/fnagi.2013.00094

Hartley, T., Bird, C. M., Chan, D., Cipolotti, L., Husain, M., Vargha-Khadem, F., \& Burgess, N. (2007). The hippocampus is required for short-term topographical memory in humans. Hippocampus, 17, 34-48. https://doi.org/10.1002/hipo.20240

Inagaki, H., Meguro, K., Shimada, M., Ishizaki, J., Okuzumi, H., \& Yamadori, A. (2002). Discrepancy Between Mental Rotation and Perspective-Taking Abilities in Normal Aging Assessed by Piaget's Three-Mountain Task. Journal of Clinical and Experimental Neuropsychology (Neuropsychology, Development and Cognition: Section A), 24(1), 18-25. https://doi.org/10.1076/jcen.24.1.18.969

King, J. A., Burgess, N., Hartley, T., Vargha-Khadem, F., \& O’Keefe, J. (2002). Human hippocampus and viewpoint dependence in spatial memory. Hippocampus, 12(6), 811-820. https://doi.org/10.1002/hipo.10070

Klencklen, G., Després, O., \& Dufour, A. (2012). What do we know about aging and spatial cognition? Reviews and perspectives. Ageing Research Reviews, 11, 123-135. https://doi.org/10.1016/j.arr.2011.10.001

Lester, A. W., Moffat, S. D., Wiener, J. M., Barnes, C. A., \& Wolbers, T. (2017). The aging navigational system. Neuron, 95, 1019-1035. https://doi.org/10.1016/j.neuron.2017.06.037

Mathôt, S., Schreij, D., \& Theeuwes, J. (2012). OpenSesame: An open-source, graphical experiment 
builder for the social sciences. Behavior Research Methods, 44(2), 314-324.

https://doi.org/10.3758/s13428-011-0168-7

Milner, A. D., \& Goodale, M. A. (2008). Two visual systems re-viewed. Neuropsychologia, 46(3), 774-785. https://doi.org/10.1016/j.neuropsychologia.2007.10.005

Mitchell, K. J., Johnson, M. K., Raye, C. L., Mather, M., \& D’Esposito, M. (2000). Aging and reflective processes of working memory: Binding and test load deficits. Psychology and Aging, 15(3), 527-541. https://doi.org/10.1037/0882-7974.15.3.527

Montefinese, M., Sulpizio, V., Galati, G., \& Committeri, G. (2015). Age-related effects on spatial memory across viewpoint changes relative to different reference frames. Psychological research, 79(4), 687-697. https://doi.org/10.1007/s00426-014-0598-9

Nasreddine, Z. S., Phillips, N. A., Bèdirian, V., Charbonneau, S., Whitehead, V., Collin, I., ... Chertkow, H. (2005). The Montreal Cognitive Assessment, MoCA: A Brief Screening Tool For Mild Cognitive Impairment. Journal of the American Geriatrics Society, 53, 695-699. https://doi.org/10.1111/j.1532-5415.2005.53221.x

Pertzov, Y., Dong, M. Y., Peich, M. C., \& Husain, M. (2012). Forgetting What Was Where: The Fragility of Object-Location Binding. PLOS ONE, 7(10). https://doi.org/10.1371/journal.pone.0048214

Pertzov, Y., Heider, M., Liang, Y., \& Husain, M. (2015). Effects of healthy ageing on precision and binding of object location in visual short term memory. Psychology and Aging, 30(1), 2635. https://doi.org/10.1037/a0038396

Postma, A., Kessels, R. P., \& van Asselen, M. (2004). The neuropsychology of object-location memory. In G. Allen (Ed.), Remembering where: Advances in understanding spatial memory 
(pp. 143-160). Mahwah, NJ: Lawrence Erlbaum Associates.

Postma, A., \& van der Ham, I. J. (2016). Neuropsychology of space: spatial functions of the human brain. Academic Press.

Vieweg, P., Stangl, M., Howard, L. R., \& Wolbers, T. (2015). Changes in pattern completion-A key mechanism to explain age-related recognition memory deficits?. Cortex, 64, 343-351. https://doi.org/10.1016/j.cortex.2014.12.007

Waller, D. E., \& Nadel, L. E. (2013). Handbook of spatial cognition. Washington, DC, US: American Psychological Association.

Waller, D. (2006). Egocentric and nonegocentric coding in memory for spatial layout: Evidence from scene recognition. Memory \& cognition, 34(3), 491-504. http://dx.doi.org/10.3758/BF03193573

Watanabe, M. (2011). Distinctive features of spatial perspective-taking in the elderly. International Journal of Aging \& Human Development, 72(3), 225-241. https://doi.org/10.2190/AG.72.3.d

Wechsler, D. (1981). Manual for the Wechsler Adult Intelligence Scale - Revised. San Antonio, TX: Psychological Corporation.

Yamamoto, N., Fox, M. J., Boys, E., \& Ord, J. (2019). Effects of Orientation Change during Environmental Learning on Age-Related Difference in Spatial Memory. Behavioural Brain Research, 365, 125-132. https://doi.org/10.1016/j.bbr.2019.03.012

Yassa, M. A., \& Stark, C. E. (2011). Pattern separation in the hippocampus. Trends in neurosciences, 34(10), 515-525. https://doi.org/10.1016/j.tins.2011.06.006 
Zimmermann \& Eschen (2017). Brain regions involved in subprocesses of small-space episodic object-location memory: a systematic review of lesion and functional neuroimaging studies. Memory, 25, 487-519, https://doi.org/10.1080/09658211.2016.1188965 


\section{Figure 1.}

PANEL A

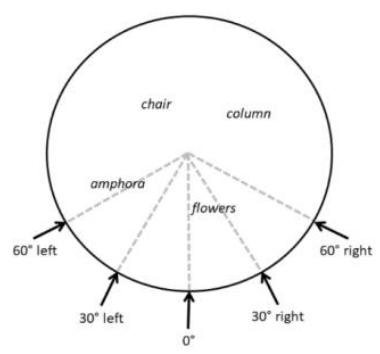

PANEL C
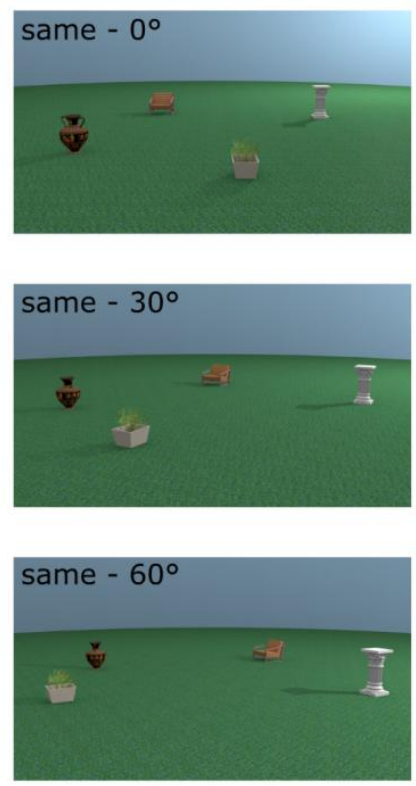

PANEL B
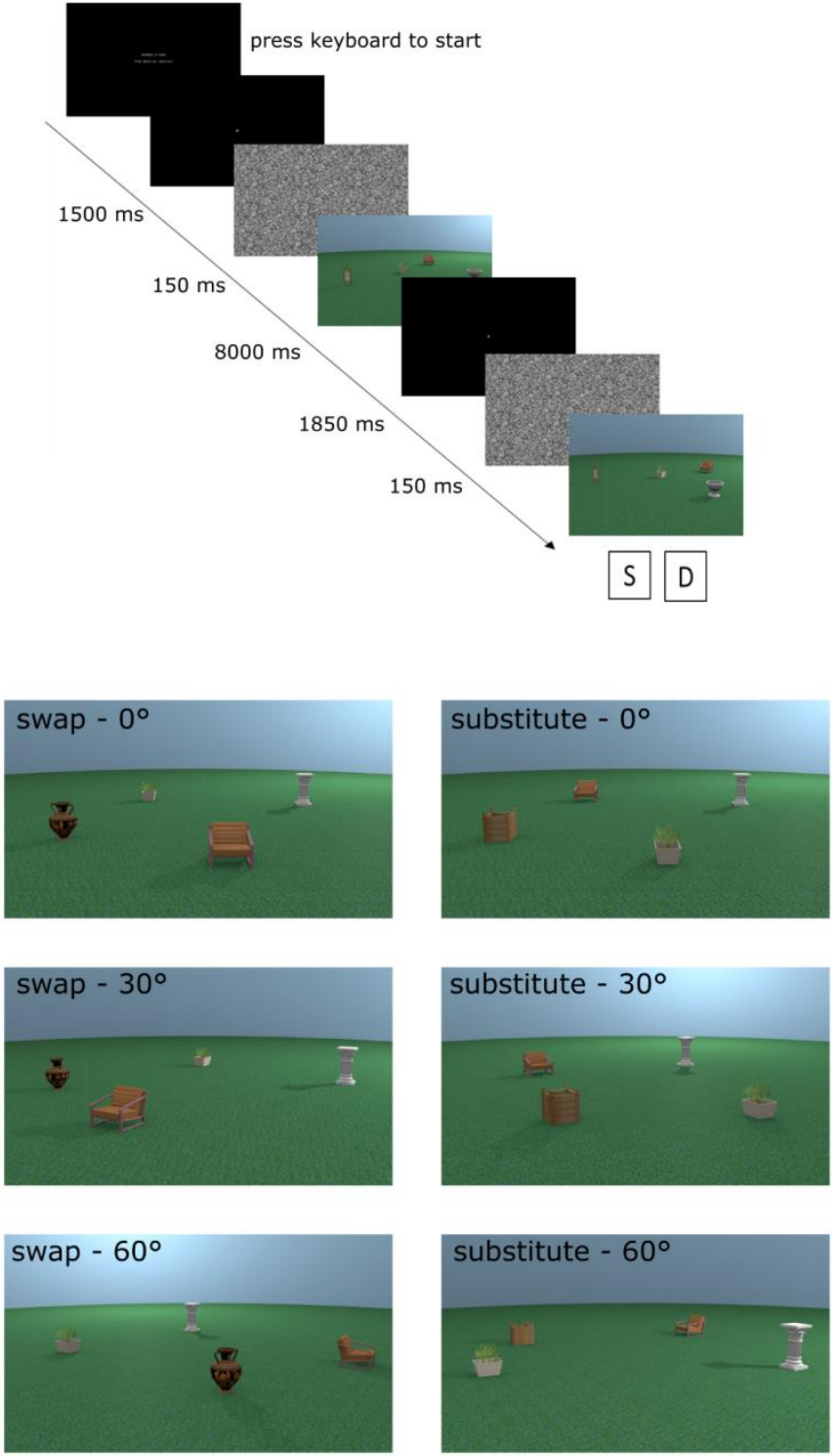
Figure 2
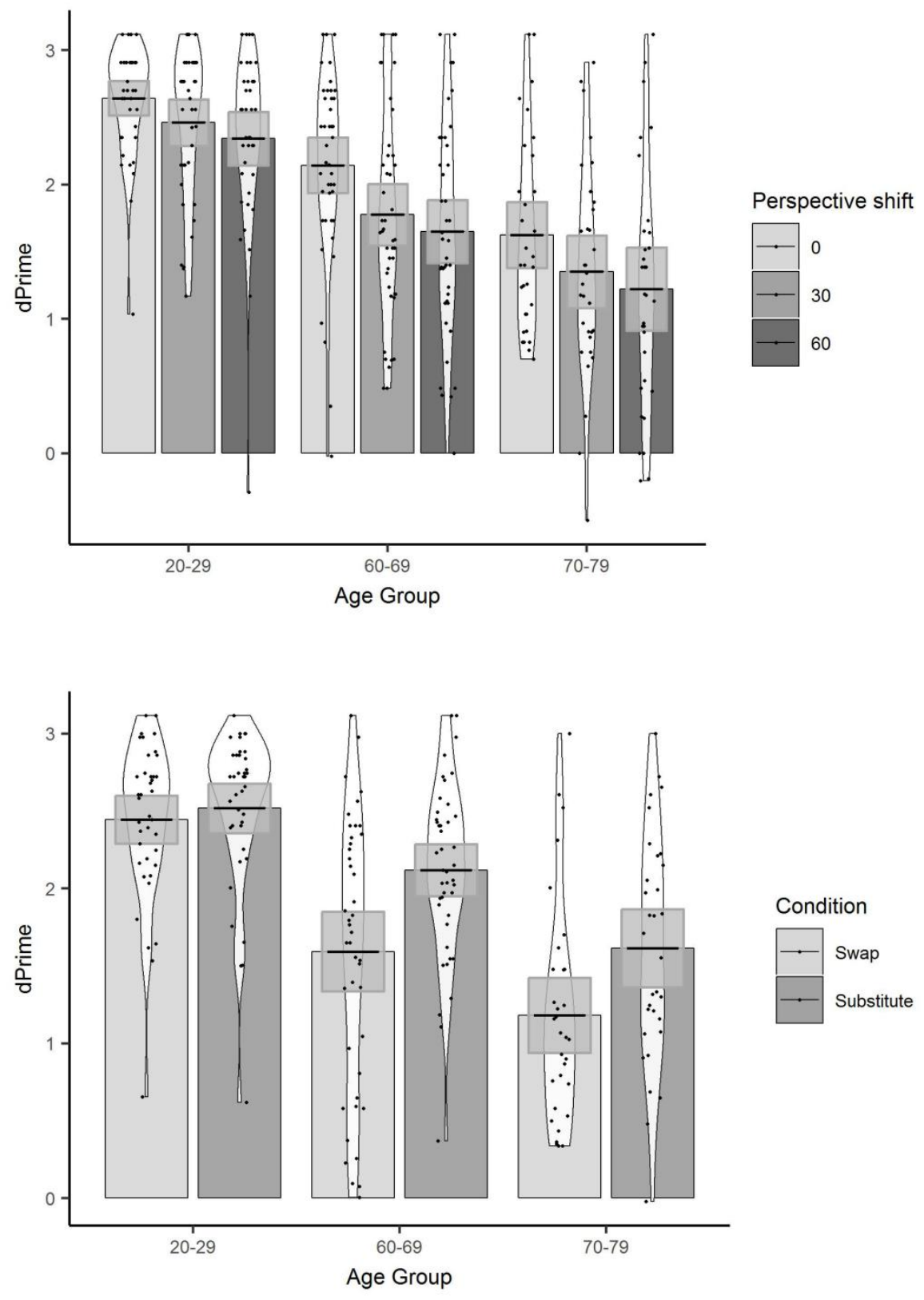
Figure 3

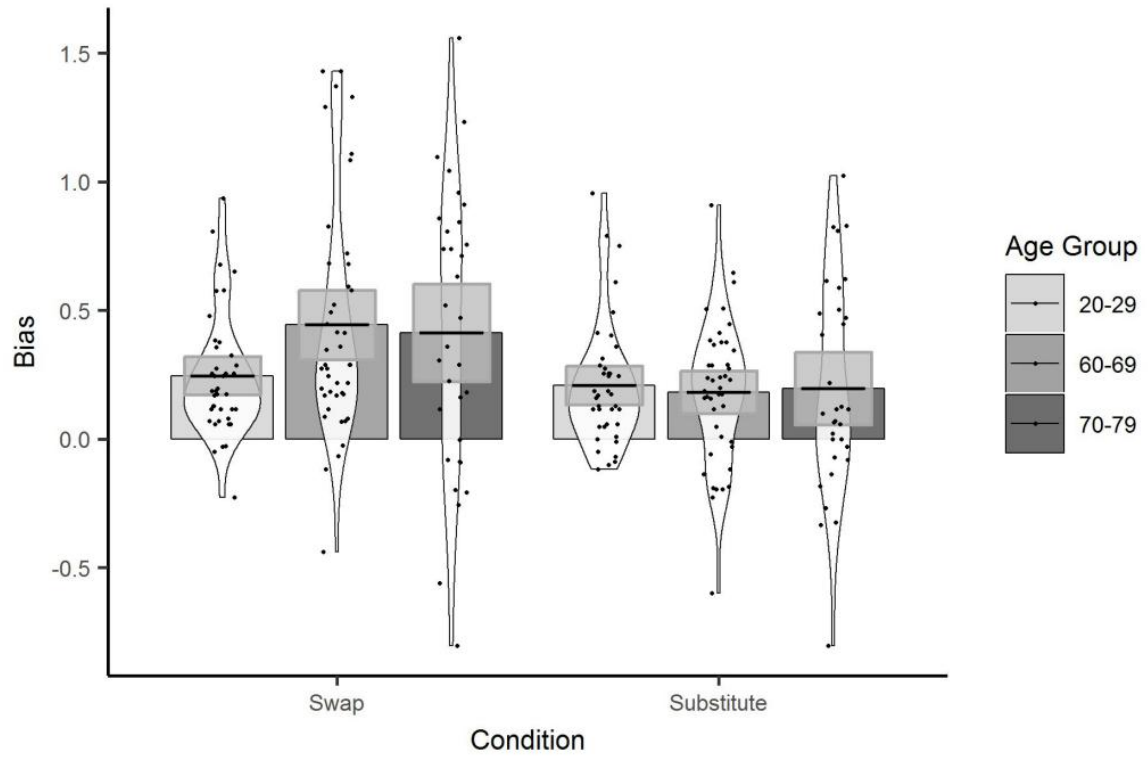


Table 1. Effect on d' scores model

Predictor

(Intercept)

Age group

$60-69$ vs. $20-29$

70-79 vs. $60-69$

Gender

Female vs. Male

Perspective

$30^{\circ}$ vs. $0^{\circ}$

$60^{\circ}$ vs. $30^{\circ}$

Condition

Substitute vs. Swap

Age group $\times$ perspective

$60-69$ vs. $20-29 \times 30^{\circ}$ vs. $0^{\circ}$

$70-79$ vs. $60-69 \times 30^{\circ}$ vs. $0^{\circ}$

$60-69$ vs. $20-29 \times 60^{\circ}$ vs. $30^{\circ}$
Coefficient SE $t$ statistic

$\begin{array}{lll}1.91 & 0.05 & 35.00\end{array}$

$\begin{array}{lll}-0.63 & 0.13 & -4.94\end{array}$

$\begin{array}{lll}-0.47 & 0.14 & -3.42\end{array}$

$0.04 \quad 0.05 \quad 0.73$

$\begin{array}{lll}-0.29 & 0.07 & -4.36\end{array}$

$\begin{array}{lll}-0.13 & 0.07 & -2.07\end{array}$

$\begin{array}{lll}-0.17 & 0.03 & -5.42\end{array}$

$\begin{array}{lll}-0.19 & 0.15 & -1.24\end{array}$

$\begin{array}{lll}0.07 & 0.17 & 0.43\end{array}$

$\begin{array}{lll}-0.01 & 0.15 & -0.08\end{array}$ 
Age group $\times$ condition

Substitute vs. Swap $\times 60-69$ vs. $20-29$

Substitute vs. Swap $\times$ 70-79 vs. 60-69

Perspective $\times$ condition

Substitute vs. Swap $\times 30^{\circ}$ vs. $0^{\circ}$

Substitute vs. Swap $\times 60^{\circ}$ vs. $30^{\circ}$

Age group $\times$ gender

Female vs. Male $\times 60-69$ vs. $20-29$

Female vs. Male $\times$ 70-79 vs. $60-69$

Perspective $\times$ gender

Female vs. Male $\times 30^{\circ}$ vs. $0^{\circ}$

Female vs. Male $\times 60^{\circ}$ vs. $30^{\circ}$

Condition $\times$ gender

Female vs. Male $\times$ Substitute vs. Swap

Age group $\times$ perspective $\times$ condition

Substitute vs. Swap $\times 60-69$ vs. $20-29 \times 30^{\circ}$ vs. $0^{\circ}$

Substitute vs. Swap $\times 70-79$ vs. $60-69 \times 30^{\circ}$ vs. $0^{\circ}$

Substitute vs. Swap $\times 60-69$ vs. $20-29 \times 60^{\circ}$ vs. $30^{\circ}$

Substitute vs. Swap $\times 70-79$ vs. $60-69 \times 60^{\circ}$ vs. $30^{\circ}$ $\begin{array}{lll}-0.23 & 0.07 & -3.21\end{array}$

$\begin{array}{lll}0.05 & 0.08 & 0.68\end{array}$

$\begin{array}{lll}-0.05 & 0.04 & -1.25\end{array}$

$\begin{array}{lll}-0.03 & 0.04 & -0.87\end{array}$

$\begin{array}{lll}0.01 & 0.13 \quad 0.04\end{array}$

$\begin{array}{lll}-0.03 & 0.14 & -0.20\end{array}$

$\begin{array}{lll}-0.01 & 0.07 & -0.10\end{array}$

$0.12 \quad 0.06 \quad 1.80$

$\begin{array}{lll}0.01 & 0.03 \quad 0.24\end{array}$

$\begin{array}{lll}-0.16 & 0.09 & -1.70\end{array}$

$\begin{array}{lll}-0.01 & 0.10 & -0.11\end{array}$

$\begin{array}{lll}0.10 & 0.09 \quad 1.07\end{array}$

$\begin{array}{lll}-0.07 & 0.10 & -0.69\end{array}$ 
Female vs. Male $\times$ Substitute vs. Swap $\times 30^{\circ}$ vs. $0^{\circ}$

Female vs. Male $\times$ Substitute vs. Swap $\times 60^{\circ}$ vs. $30^{\circ}$

Age group $\times$ gender $\times$ perspective

$60-69$ vs. $20-29 \times$ Female vs. Male $\times 30^{\circ}$ vs. $0^{\circ}$

$70-79$ vs. $60-69 \times$ Female vs. Male $\times 30^{\circ}$ vs. $0^{\circ}$

$60-69$ vs. $20-29 \times$ Female vs. Male $\times 60^{\circ}$ vs. $30^{\circ}$

$70-79$ vs. $60-69 \times$ Female vs. Male $\times 60^{\circ}$ vs. $30^{\circ}$

Age group $\times$ gender $\times$ condition

60-69 vs. $20-29 \times$ Female vs. Male $\times$ Substitute vs. Swap

70-79 vs. $60-69 \times$ Female vs. Male $\times$ Substitute vs. Swap

Age group $\times$ gender $\times$ perspective $\times$ condition

$60-69$ vs. $20-29 \times$ Female vs. Male $\times 30^{\circ}$ vs. $0^{\circ} \times$ Substitute vs. Swap

$70-79$ vs. $60-69 \times$ Female vs. Male $\times 30^{\circ}$ vs. $0^{\circ} \times$ Substitute vs. Swap

$60-69$ vs. $20-29 \times$ Female vs. Male $\times 60^{\circ}$ vs. $30^{\circ} \times$ Substitute vs.

0.04

0.09

0.42

Swap

$70-79$ vs. $60-69 \times$ Female vs. Male $\times 60^{\circ}$ vs. $30^{\circ} \times$ Substitute vs.

$-0.08$

0.10

$-0.78$

$\begin{array}{lll}-0.00 & 0.04 & -0.01\end{array}$

$0.01 \quad 0.04 \quad 0.33$

$\begin{array}{lll}-0.09 & 0.15 & -0.59\end{array}$

$0.30 \quad 0.16 \quad 1.83$

$\begin{array}{lll}-0.07 & 0.15 & -0.43\end{array}$

$0.17 \quad 0.16 \quad 1.06$

$\begin{array}{lll}-0.05 & 0.07 & -0.70\end{array}$

$\begin{array}{lll}-0.04 & 0.08 & -0.58\end{array}$

$\begin{array}{lll}-0.01 & 0.09 & -0.07\end{array}$

$\begin{array}{lll}0.01 & 0.10 \quad 0.10\end{array}$ Swap

Note. $|\mathrm{t}|>1.96$ in bold. 
Table 2. Effect on response bias model

Predictor

(Intercept)

Age group

$60-69$ vs. $20-29$

70-79 vs. $60-69$

Gender

Female vs. Male

Perspective

$$
\begin{aligned}
& 30^{\circ} \text { vs. } 0^{\circ} \\
& 60^{\circ} \text { vs. } 30^{\circ}
\end{aligned}
$$

Condition

Substitute vs. Swap

0.08

$\begin{array}{ccc}0.09 & 0.07 & 1.18 \\ -0.03 & 0.08 & -0.36\end{array}$

$0.01 \quad 0.03 \quad 0.40$

$\begin{array}{lll}-0.23 & 0.04 & -5.24\end{array}$

$\begin{array}{lll}-0.12 & 0.03 & -3.83\end{array}$

Age group $\times$ perspective

$60-69$ vs. $20-29 \times 30^{\circ}$ vs. $0^{\circ}$

$70-79$ vs. $60-69 \times 30^{\circ}$ vs. $0^{\circ}$

$60-69$ vs. $20-29 \times 60^{\circ}$ vs. $30^{\circ}$

$70-79$ vs. $60-69 \times 60^{\circ}$ vs. $30^{\circ}$

Age group $\times$ condition

Substitute vs. Swap $\times 60-69$ vs. $20-29$

Substitute vs. Swap $\times$ 70-79 vs. 60-69
0.1

$\begin{array}{lll}-0.23 & 0.11 & -2.12\end{array}$

$\begin{array}{lll}-0.20 & 0.07 & -2.72\end{array}$

$\begin{array}{lll}-0.03 & 0.08 & -0.34\end{array}$

\begin{tabular}{lll}
-0.13 & 0.10 & -1.33 \\
$-\mathbf{0 . 2 3}$ & $\mathbf{0 . 1 1}$ & $\mathbf{- 2 . 1 2}$ \\
$\mathbf{- 0 . 2 0}$ & $\mathbf{0 . 0 7}$ & $\mathbf{- 2 . 7 2}$ \\
\hline-0.03 & 0.08 & -0.34
\end{tabular}

$\begin{array}{ccc}\mathbf{0 . 1 2} & \mathbf{0 . 0 4} & \mathbf{3 . 2 0} \\ -0.03 & 0.04 & -0.68\end{array}$


Perspective $\times$ condition

Substitute vs. Swap $\times 30^{\circ}$ vs. $0^{\circ}$

Substitute vs. Swap $\times 60^{\circ}$ vs. $30^{\circ}$

Age group $\times$ gender

Female vs. Male $\times 60-69$ vs. $20-29$

Female vs. Male $\times 70-79$ vs. $60-69$

Perspective $\times$ gender

Female vs. Male $\times 30^{\circ}$ vs. $0^{\circ}$

Female vs. Male $\times 60^{\circ}$ vs. $30^{\circ}$

Condition $\times$ gender

Female vs. Male $\times$ Substitute vs. Swap

Age group $\times$ perspective $\times$ condition

Substitute vs. Swap $\times 60-69$ vs. $20-29 \times 30^{\circ}$ vs. $0^{\circ}$

Substitute vs. Swap $\times 70-79$ vs. $60-69 \times 30^{\circ}$ vs. $0^{\circ}$

Substitute vs. Swap $\times 60-69$ vs. $20-29 \times 60^{\circ}$ vs. $30^{\circ}$

Substitute vs. Swap $\times 70-79$ vs. $60-69 \times 60^{\circ}$ vs. $30^{\circ}$

Gender $\times$ perspective $\times$ condition

Female vs. Male $\times$ Substitute vs. Swap $\times 30^{\circ}$ vs. $0^{\circ}$

Female vs. Male $\times$ Substitute vs. Swap $\times 60^{\circ}$ vs. $30^{\circ}$

Age group $\times$ gender $\times$ perspective

$60-69$ vs. $20-29 \times$ Female vs. Male $\times 30^{\circ}$ vs. $0^{\circ}$ $\begin{array}{lll}0.02 & 0.02 \quad 1.25\end{array}$

$\begin{array}{lll}0.02 & 0.02 & 0.87\end{array}$

$\begin{array}{lll}-0.02 & 0.07 & -0.22\end{array}$

$\begin{array}{lll}0.18 & 0.08 & 2.36\end{array}$

$\begin{array}{lll}0.02 & 0.04 & 0.39\end{array}$

$0.04 \quad 0.03 \quad 1.20$

$\begin{array}{lll}-0.00 & 0.02 & -0.24\end{array}$

$\begin{array}{lll}0.08 & 0.05 & 1.69\end{array}$

$\begin{array}{lll}0.01 & 0.05 & 0.11\end{array}$

$\begin{array}{lll}-0.05 & 0.05 & -1.07\end{array}$

$0.03 \quad 0.05 \quad 0.69$

$\begin{array}{lll}0.00 & 0.02 \quad 0.01\end{array}$

$\begin{array}{lll}-0.01 & 0.02 & -0.33\end{array}$

$\begin{array}{lll}-0.04 & 0.10 & -0.36\end{array}$ 
$70-79$ vs. $60-69 \times$ Female vs. Male $\times 30^{\circ}$ vs. $0^{\circ}$

$60-69$ vs. $20-29 \times$ Female vs. Male $\times 60^{\circ}$ vs. $30^{\circ}$

$70-79$ vs. $60-69 \times$ Female vs. Male $\times 60^{\circ}$ vs. $30^{\circ}$
$0.09 \quad 0.11 \quad 0.83$

$\begin{array}{lll}-0.05 & 0.07 & -0.70\end{array}$

$0.09 \quad 0.08$

Age group $\times$ gender $\times$ condition

60-69 vs. $20-29 \times$ Female vs. Male $\times$ Substitute vs. Swap

70-79 vs. $60-69 \times$ Female vs. Male $\times$ Substitute vs. Swap

$0.02 \quad 0.04 \quad 0.58$

Age group $\times$ gender $\times$ perspective $\times$ condition

$60-69$ vs. $20-29 \times$ Female vs. Male $\times 30^{\circ}$ vs. $0^{\circ} \times$ Substitute vs. Swap

$\begin{array}{lll}0.00 & 0.05 & 0.07\end{array}$

$70-79$ vs. $60-69 \times$ Female vs. Male $\times 30^{\circ}$ vs. $0^{\circ} \times$ Substitute vs Swap

$\begin{array}{lll}-0.01 & 0.05 & -0.10\end{array}$

$60-69$ vs. $20-29 \times$ Female vs. Male $\times 60^{\circ}$ vs. $30^{\circ} \times$ Substitute vs. Swap

$\begin{array}{lll}-0.02 & 0.05 & -0.42\end{array}$

$70-79$ vs. $60-69 \times$ Female vs. Male $\times 60^{\circ}$ vs. $30^{\circ} \times$ Substitute vs. Swap 


\section{Figure legends}

\section{Fig. 1. Places and conditions in the place recognition task}

Panel A: schematic drawing of possible viewpoints from which the place was rendered (the circle represents the area in which objects could be located. The arrows indicate the direction of the cameras for the rendering); Panel B: sequence of a trial; Panel C: Object and perspective manipulations referred to place 1. Place 1 had a chair, a column, an amphora, and flowers. The second place featured a lion statue, a vase, a table, and a basket. The third place featured a basket, the flowers, a chair, and a vase. The fourth place featured a bust, a lion statue, a box, and a table. The fifth, the flowers, a vase, an amphora, and a box. The sixth, a chair, a basket, a column, and a bust. The seventh, a column, a table, a basket, and an amphora. The eighth, a vase, a bust, a box, and a lion statue. Light and shadows changed accordingly to the perspective shift in the place.

Fig.2. Age group $\times$ perspective (Panel A) and age group $\times$ condition (Panel B) plots

Plots are mean averages with confidence interval error bars, individual data points and density profiles.

Fig.3. Bias scores plot for age group $\times$ condition interaction 